\title{
Pengaruh iklim organisasi sekolah, budaya kerja guru, dan kepuasan kerja terhadap komitmen kerja guru
}

\author{
Ilham Syahputra Saragih 1 , Dedi Suhendro * 2 \\ ${ }^{1}$ Sistem Informasi, STIKOM Tunas Bangsa. \\ J1. Sudirman, Proklamasi, Siantar Barat, Pematang Siantar, Sumatera Utara 21143, Indonesia. \\ 2 Program Studi Komputerisasi Akuntansi AMIK Tunas Bangsa. \\ Jl. Sudirman, Banjar, Siantar Barat, Pematang Siantar, Sumatera Utara 21142, Indonesia. \\ dedi.su@amiktunasbangsa.ac.id \\ * Corresponding Author
}

\section{ARTICLE INFO}

\section{Article History}

Received:

2 February 2019;

Revised:

16 June 2020;

Accepted:

4 July 2020

\section{Keywords}

Budaya kerja;

Iklim organisasi;

Kepuasan kerja;

Komitmen kerja;

Job culture;

Organization climate;

Job satisfaction;

Job commitment

\begin{abstract}
Tujuan penelitian ini untuk mengetahui pengaruh iklim organisasi sekolah, budaya kerja guru, kepuasan kerja terhadap komitmen kerja guru baik secara parsial maupun secara simultan. Penelitian ini menggunakan metode kuantitatif, sampel dari penelitian ini keseluruhan populasi semua guru SMA Negeri I Dolok Batu Nanggar yang berjumlah 52 orang guru. Teknik pengumpulan data yang penulis lakukan dalam penelitian ini dengan melakukan pengamatan langsung ke lokasi penelitian untuk memperoleh gambaran suasana tempat kerja, proses kerja dan hal-hal lain yang diperlukan serta membagikan kuisioner atau angket penelitian kepada seluruh populasi sebanyak 52 orang guru SMA Negeri I Dolok Batu Nanggar. Teknik analisis data dalam penelitian ini menggunakan analisis deskriptif dan analisis regresi linier berganda. Hasil penelitian ini menjelaskan bahwa variabel iklim organisasi sekolah berpengaruh positif dan signifikan terhadap komitmen kerja guru sebesar $19 \%$. Variabel budaya kerja berpengaruh positif dan signifikan terhadap komitmen kerja guru $29.90 \%$. Variabel kepuasan kerja guru berpengaruh positif dan signifikan terhadap komitmen kerja guru $61 \%$. Variabel iklim organisasi sekolah, budaya kerja dan kepuasaan kerja guru berpengaruh positif dan signifikan terhadap komitmen kerja guru sebesar $71.20 \%$, sedangkan sisanya sebesar $28.80 \%$ dipengaruhi oleh faktor-faktor lain yang tidak diteliti.
\end{abstract}

The purpose of this study was to determine the effect of organizational climate, job culture teachers, job satisfaction of high school to job commitment of teachers either partially or simultaneously. This study uses quantitative methods, the sample of this study is the overall population of all teachers in high school 1 of Dolok Batu Nanggar totaling 52 teachers. The data collection techniques used in this study were direct observations to the research location to get a picture of the atmosphere of the workplace, work processes, and other things needed and to distribute questionnaire research to the entire population of 52 teachers in high school 1 of Dolok Batu Nanggar. Data analysis techniques in this study used descriptive analysis and multiple linear regression analysis. The result variable of the organizational climate of school influence positive and significant to job commitment of teachers is $19 \%$. Job culture teachers' variable influence positive and significant to job commitment of teachers is $29.90 \%$. Job satisfaction of high school variable influence positive and significant to job commitment of teachers is $61 \%$. Variable of organization climate of school, job culture teachers, and job satisfaction of high school influence to job commitment of teachers is $71.20 \%$, while the remaining is $28.80 \%$ influenced by other factors not examined.

This is an open access article under the CC-BY-SA license.

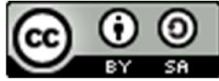

How to cite:

Saragih, I. S., \& Suhendro, S. (2020). Pengaruh iklim organisasi sekolah, budaya kerja guru, dan kepuasan kerja terhadap komitmen kerja guru. Jurnal Akuntabilitas Manajemen Pendidikan, 8(1), 44-52.

doi:https://doi.org/10.21831/jamp.v8i1.29654 


\section{PENDAHULUAN}

Ilmu pengetahuan merupakan hal yang berlangsung secara berkelanjutan sejak seseorang masih berada dalam lingkungan keluarga. Pendidikan secara formal dimulai ketika seorang anak memasuki Sekolah Dasar sampai dengan Sekolah Menengah Atas (SMA) baru dilanjutkan ke Perguruan Tinggi. Dunia pendidikan tidak dapat dipisahkan akan keberadaan seorang guru di suatu lembaga pendidikan. Iklim organisasi sebagai suatu yang dapat diukur pada lingkungan kerja baik langsung atau tidak langsung, sehingga berpengaruh pada guru dan pekerjaannya di mana tempat mereka bekerja dengan asumsi akan berpengaruh pada motivasi dan perilaku guru. Menurut Setiawan (2015) iklim organisasi yang merupakan karakteristik yang berasal dari lingkungan, sehingga berpengaruh terhadap tingkah laku orang yang berada dalam organisasi serta segala sesuatu yang ada dalam organisasi seperti sistem formal, gaya kepemimpinan manajer (informal atau formal), faktor lingkungan penting lainnya yang akan berpengaruh terhadap sikap, kepercayaan, nilai dan motivasi orang yang bekerja dalam organisasi tersebut.

Sedangkan menurut Nurhasnawati dan Subhan (2018) iklim organisasi merupakan kualitas lingkungan internal organisasi yang secara relatif terus berlangsung, dialami oleh anggota organisasi, mempengaruhi perilaku mereka dan dapat dilukiskan dalam pengertian satu set karakteristik atau sifat organisasi. Faktor-faktor yang mempengaruhi iklim organisasi, diantaranya: 1.) Manajer/pimpinan, pada dasarnya setiap tindakan yang diambil oleh pimpinan atau manajer mempengaruhi aturan-aturan, kebijakan, dan prosedur-prosedur organisasi terutama masalahmasalah yang berhubungan dengan masalah personalia, distribusi imbalan, gaya komunikasi; 2.) Tingkah laku, tingkah laku guru mempengaruhi iklim melalui kepribadian, terutama kebutuhan dan tindakan yang di lakukan untuk memuaskan kebutuhan. Komunikasi guru memainkan bagian penting dalam membentuk iklim. Cara seseorang berkomunikasi menentukan tingkat sukses atau gagalnya hubungan antar manusia; dan 3.) Faktor eksternal organisasi, sejumlah faktor eksternal organisasi mempengaruhi iklim pada organisasi. Keadaan ekonomi adalah faktor utama yang mempengaruhi iklim.

Iklim organisasi di sekolah merupakan sesuatu yang penting karena dapat menjembatani praktik-praktik pengelolaan sumber daya manusia dan produktivitasnya. Perubahan iklim di sekolah akan mempengaruhi komitmen kerja dan perilaku guru (Robbins \& Judge, 2012). Fenomena tentang iklim organisasi di SMA Negeri I Dolok Batu Nanggar diantaranya tanggung jawab guru terhadap mata pelajaran yang diampu belum sesuai harapan dan suasana sekolah karena belum menunjukkan iklim yang kondusif dalam proses belajar mengajar. Budaya pada dasarnya sebagai suatu dasar bersama yang dipelajari kelompok tertentu untuk mengatasi masalah baik eksternal atau internal kepada anggota baru sebagai cara yang tepat memahami, memikirkan dan merasakan terkait dengan masalah (Rizqina, Adam, \& Chan, 2017).

Sedangkan menurut Mahanani, Lubis, dan Widiartanto (2014) budaya kerja merupakan kebiasaan yang dilakukan berulang-ulang oleh pegawai dalam suatu organisasi, pelanggaran terhadap kebiasaan ini memang tidak ada sangsi tegas, namun dari pelaku organisasi secara moral telah menyepakati bahwa kebiasaan tersebut merupakan kebiasaan yang harus ditaati dalam rangka pelaksanaan pekerjaan untuk mencapai tujuan. Budaya kerja pada dasarnya merupakan nilai-nilai yang menjadi kebiasaan seseorang dan menentukan kualitas seseorang dalam bekerja. Nilai-nilai itu dapat berasal dari adat kebiasaan, ajaran agama, norma dan kaidah yang berlaku dalam masyarakat. Dimensi budaya kerja dapat dibagi menjadi 2, yaitu: Sikap terhadap pekerjaan, yakni kesukaan akan kerja dibandingkan kegiatan lain, seperti bersantai, atau semata-mata memperoleh kepuasan dari kesibukan pekerjaannya sendiri, atau terpaksa melakukan sesuatu hanya untuk kelangsungan hidupnya, dan perilaku pada waktu bekerja, seperti rajin, berdedikasi, bertanggungjawab, berhatihati, teliti, cermat, kemauan yang kuat untuk mempelajari tugas dan kewajibannya, suka membantu sesama guru, atau sebaliknya.

Dimensi sikap guru terhadap pekerjaan memiliki indikator-indikator meliputi mau menerima arahan pimpinan, senang menerima tanggung jawab kerja, kerja sebagai ibadah, melaksanakan pekerjaan sesuai tugas, dapat mengatasi kendala kerja, dapat menyusun laporan kerja. Disimpulkan dari defenisi diatas bahwa seorang guru yang memiliki budi pekerti, taat pada agama, dan memiliki nilai-nilai luhur akan mempunyai kinerja yang baik, dalam arti mau bekerja keras, jujur, anti KKN, 
serta selalu berupaya memperbaiki kualitas hasil pekerjaannya demi kemajuan profesinya. Budaya kerja guru di sekolah unggul akan menjadi optimal, bilamana didukung oleh kepala sekolah, guru, maupun siswa. Kinerja guru akan lebih bermakna bila dibarengi akan kekurangan yang ada pada dirinya, dan berupaya untuk dapat meningkatkan atas kekurangan tersebut sebagai upaya meningkatkan ke arah yang lebih baik (Manzoor, Ullah, Hussain, \& Ahmad, 2011). Budaya kerja yang dilakukan di sekolah dapat berupa membuat dan mempersiapkan administrasi guru, pelaksanaan proses belajar mengajar, serta pelaksanaan evaluasi pembelajaran. Sarana yang sangat penting pada manjemen sumber daya manusia dalam suatu orgaisasi adalah terciptanya kepuasan kerja dari pegawai atau karyawan (Iqbal, Ehsan, Rizwan, \& Noreen, 2014).

Budaya kerja guru pada SMA Negeri I Dolok Batu Nanggar terlihat masih ada permasalahan seperti penguasaan untuk pelajaran yang terdiri atas penguasaan bahan dan konsep-konsep keilmuan yang harus diajarkan belum baik, kemampuan mengelola program belajar mengajar belum baik, dan kemampuan mengelola dan menggunakan media dan sumber belajar belum optimal. Kepuasan kerja merupakan suatu ungkapan rasa, sikap seseorang terhadap pekerjaannya, kesempatan promosi, dengan rekan kerja, pengawasan dan perasaan puas sehingga kepuasan kerja lebih mencerminkan sifat daripada perilaku dalam menjalankan pekerjaannya masing-masing (Widyastuti \& Palupiningdyah, 2018).

Menurut Ilahi, Mukzam, dan Prasetya (2017) kepuasan kerja merupakan suatu perasaaan positif tentang pekerjaan seseorang yang merupakan hasil dari sebuah evaluasi karakteristiknyayang menggambarkan keadaaan emosional karyawan dimana terjadi ataupun tidak terjadi titik temu antara nilai balas jasa karyawan dari perusahaan/organisasi dengan tingkat nilai balas jasa yang memang diinginkan oleh karyawan yang bersangkutan. Penelitian yang dilakukan oleh Muayyad dan Gawi (2016) menyatakan bahwa kepuasan kerja merupakan seperangkat perasaan pegawai tentang menyenangkan atau tidaknya pekerjaan mereka yang pada umumnya mengacu pada sikap seorang terhadap kepuasan kerja yang menunjukkan kesesuaian antara harapan dan imbalan yang disediakan. Faktor-faktor yang memberikan kepuasan kerja antara lain: 1.) Faktor individual, meliputi umur, kesehatan, watak, dan harapan; 2.) Faktor sosial, meliputi hubungan kekeluargaan, pandangan masyarakat, kesempatan bereaksi, kegiatan perserikatan pekerja, kebebasan berpolitik, dan hubungan kemasyarakatan; dan 3.) Faktor utama dalam pekerjaan, meliputi upah, pengawasan, ketentraman kerja, kondisi kerja, dan kesempatan untuk maju.

Kepuasan kerja guru merupakan gejala kompleks yang memiliki berbagai faktor hingga saling berhubungan diantaranya personal, sosial, budaya dan ekonomi. Kepuasan kerja guru juga merupakan hasil dari berbagai sikap seorang guru terhadap pekerjaannya dan faktor-faktor yang berhubungan dengan pekerjaannya. Kepuasan kerja guru ditunjukkan oleh sikapnya dalam bekerja atau mengajar. Jika guru puas akan keadaan yang mempengaruhinya, maka akan bekerja atau mengajar dengan baik. SMA Negeri I Dolok Batu Nanggar harus berusaha meningkatkan kuantitas maupun kualitas dari para guru. Peran guru sebagai pelaku utama dalam bekerja sangatlah besar, terutama untuk mendukung sektor lainnya. Dengan sumber daya yang berkualitas, maka kualitas yang tinggi dapat dimiliki oleh SMA Negeri I Dolok Batu Nanggar, sehingga menghasilkan output yang berkualitas sesuai dengan tuntutan yang terus berkembang pada saat ini. Berdasarkan data yang diperoleh dari SMA Negeri I Dolok Batu Nanggar diperoleh tingkat absensi guru lebih dari dari 5\% perlu dihindari karena dapat mengganggu kelancaran pelayanan kepada instansi terkait, oleh karena itu kepala sekolah menerapkan pemberian sangsi bagi guru absen dengan memberikan teguran setiap satu kali absen.

Komitmen kerja merupakan perasaan identifikasi, loyalitas dan keterlibatan yang ditunjukkan oleh pekerja terhadap organisasi atau unit organisasi. Komitmen pada organisasi menyangkut tiga sikap yaitu: 1.) Perasaan identifikasi dengan tujuan organisasi; 2.) Perasaan keterlibatan dalam tugas organisasi; dan 3.) Perasaan loyalitas untuk organisasi (Putri, 2014). Sedangkan menurut Puspitasari dan Asyanti (2011) menyatakan bahwa seseorang yang memiliki komitmen kerja yang tinggi akan memiliki kemauan secara sadar untuk mencurahkan usaha demi kepentingan organisasi sehingga karyawan bekerja bukan karena adanya instruksi melainkan termotivasi dari dalam diri sendiri.

Kekuatan batin yang datang dari dalam hati seorang guru dan kekuatan dari luar itu sendiri tentang tugasnya sehingga dapat memberikan pengaruh terhadap sikap guru seperti tanggung jawab dan responsive, inovatif terhadap perkembangan ilmu pengetahuan dan teknologi yang merupakan 
komitmen kerja dari seorang guru (Steers \& Porter, 2008). Dari uraian tersebut dapat disimpulkan bahwa komitmen kerja guru merupakan suatu keterikatan diri terhadap tugas dan kewajiban sebagai guru dengan rasa tanggung jawab, responsive dan inovatif terhadap perkembangan ilmu pengetahuan dan teknologi. Komitmen tersebut terdapat beberapa unsur antara lain adanya kemampuan memahami diri dan tugasnya, baik kekuatan dari dalam (pancaran sikap batin) dan kekuatan dari luar (tanggap terhadap perubahan). Unsur inilah yang mendorong rasa tanggung jawab terhadap tugas, kewajiban yang menjadi komitmen seseorang sehingga tugas tersebut dilakukan dengan penuh keikhlasan. SMA Negeri I Dolok Batu Nanggar dalam menjalankan proses belajar mengajarnya tidak terlepas dari komitmen kerja para guru dalam mendidik atau mengajar para siswa-siswi.

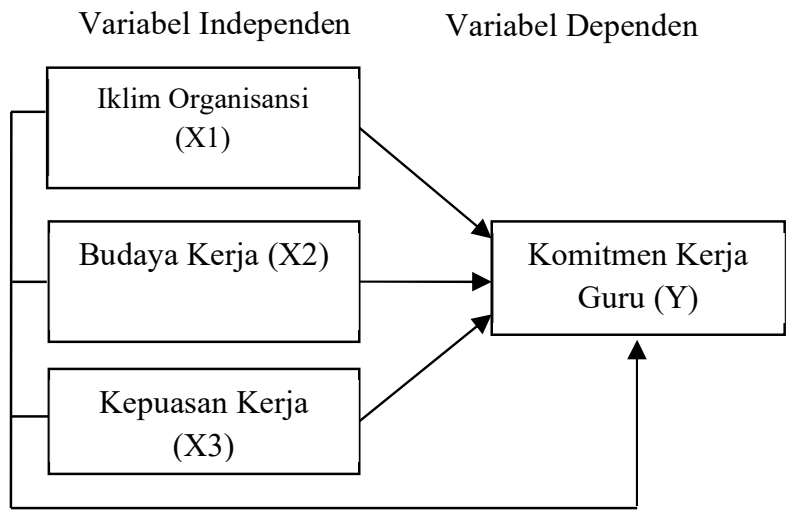

Gambar 1. Kerangka Konseptual

Sebagaimana pada gambar 1, tujuan penelitian yakni untuk mengetahui pengaruh iklim organisasi sekolah terhadap komitmen kerja guru SMA Negeri I Dolok Batu Nanggar, pengaruh budaya kerja guru terhadap komitmen kerja guru SMA Negeri I Dolok Batu Nanggar, pengaruh kepuasan kerja terhadap komitmen kerja guru SMA Negeri I Dolok Batu Nanggar, dan pengaruh iklim organisasi sekolah, budaya kerja guru dan kepuasan kerja terhadap komitmen kerja guru SMA Negeri I Dolok Batu Nanggar. Adapun hipotesis penelitian ini yakni: 1.) Iklim organisasi sekolah berpengaruh positif dan signifikan terhadap komitmen kerja guru SMA Negeri I Dolok Batu Nanggar; 2.) Budaya kerja guru berpengaruh positif dan signifikan terhadap komitmen kerja guru SMA Negeri I Dolok Batu Nanggar; dan 3.) Kepuasan kerja berpengaruh positif dan signifikan terhadap komitmen kerja guru SMA Negeri I Dolok Batu Nanggar. Dengan begitu, iklim organisasi sekolah, budaya kerja guru dan kepuasan kerja berpengaruh positif dan signifikan terhadap komitmen kerja guru SMA Negeri I Dolok Batu Nanggar.

\section{METODE}

Lokasi penelitian dilakukan di SMA Negeri I Dolok Batu Nanggar Jalan Sisingamangaraja No. 1 Serbelawan Kabupaten Simalungun. Objek penelitian ini adalah guru SMA Negeri I Dolok Batu Nanggar, di mana penelitian ini merupakan penelitian sebab akibat yaitu penelitian yang tujuan untuk menganalisis pengaruh tiga variabel bebas (independen) terhadap satu variabel terikat (dependen). Adapun variabel bebas yang dimaksud dalam penelitian ini adalah iklim organisasi sekolah sebagai variabel $\left(\mathrm{X}_{1}\right)$, budaya kerja guru sebagai variabel $\left(\mathrm{X}_{2}\right)$, kepuasan kerja sebagai variabel $\left(\mathrm{X}_{3}\right)$ dan komitmen kerja guru sebagai variabel $(\mathrm{Y})$ yang merupakan variabel terikat. Berdasarkan pada Tabel 1, data guru bahwa sampel dalam penelitian ini adalah keseluruhan populasi, jumlah guru di Sekolah Menengah Atas Negeri I Dolok Batu Nanggar sebanyak 52 orang. Teknik pengumpulan data yang penulis lakukan dalam penelitian ini dengan melakukan pengamatan langsung ke lokasi.

Penelitian dilakukan untuk memperoleh gambaran suasana tempat kerja, proses kerja dan hal-hal lain yang diperlukan serta membagikan kuisioner/angket penelitian kepada seluruh populasi 
48 - Jurnal Akuntabilitas Manajemen Pendidikan

sebanyak 52 orang guru SMA Negeri I Dolok Batu Nanggar. Teknik analisis data dalam penelitian ini menggunakan analisis deskriptif dan analisis regresi linier berganda.

Tabel 1. Sampel Guru SMA Negeri 1 Dolok Batu Nanggar

\begin{tabular}{|c|c|c|}
\hline No & Keterangan & Jumlah \\
\hline 1 & Wakil Kepala Sekolah & 4 \\
\hline 2 & Wali Kelas & 28 \\
\hline 3 & Guru & 20 \\
\hline & Jumlah & 52 \\
\hline
\end{tabular}

\section{HASIL DAN PEMBAHASAN}

Hasil

Pengaruh Iklim Organisasi Sekolah terhadap Komitmen Kerja Guru

Untuk mengetahui pengaruh iklim organisasi sekolah terhadap komitmen kerja guru di SMA Negeri I Dolok Batu Nanggar digunakan uji-t, sedangkan untuk melihat besarnya pengaruh digunakan angka beta atau standardized coefficient.

Tabel 2. Coeficients ${ }^{\mathrm{a}}$ Pengaruh Iklim Organisasi Sekolah terhadap Komitmen Kerja Guru

\begin{tabular}{llccccc}
\hline \multirow{2}{*}{ Model } & \multicolumn{2}{c}{ Unstandardized Coefficients } & \multicolumn{2}{c}{$\begin{array}{c}\text { Standardized Coefficients } \\
\text { Beta }\end{array}$} & \multirow{2}{*}{ Sig. } \\
\cline { 2 - 4 } & \multicolumn{1}{c}{$\mathrm{B}$} & Std. Error & & & \\
\hline \multirow{2}{*}{1} & (Constant) & -3.903 & 4.565 & & -.855 & .397 \\
& Iklim organisasi & .220 & .087 & .205 & 2.516 & .015 \\
\hline
\end{tabular}

a Dependent variable: Komitmen kerja

Berdasarkan Tabel 2 diperoleh nilai thitung sebesar 2.516. Penelitian ini menggunakan taraf signifikansi $(\alpha ; 0,05)$ dan derajat kebebasan (DK) dengan ketentuan $\mathrm{DK}=\mathrm{n}-2$, atau $52-2=50$. Dengan ketentuan tersebut, diperoleh nilai $t_{\text {tabel }}$ sebesar 1.852. Dengan kriteria hipotesis jika $t_{\text {hitung }}>$ $t_{\text {tabel}}$, maka $\mathrm{H}_{0}$ ditolak dan $\mathrm{H}_{\mathrm{a}}$ diterima dan Jika $\mathrm{t}_{\text {hitung }}<\mathrm{t}_{\text {tabel, }}$, maka $\mathrm{H}_{0}$ diterima dan $\mathrm{H}_{\mathrm{a}}$ ditolak.

\section{Pengaruh Budaya Kerja Guru terhadap Komitmen kerja Guru}

Untuk mengetahui pengaruh budaya kerja guru terhadap komitmen kerja guru di SMA Negeri I Dolok Batu Nanggar digunakan uji-t, sedangkan untuk melihat besarnya pengaruh digunakan angka beta atau standardized coefficient.

Tabel 3. Coeficients ${ }^{\mathrm{a}}$ Pengaruh Budaya Kerja Guru terhadap Komitmen Kerja

\begin{tabular}{|c|c|c|c|c|c|c|}
\hline & \multirow[b]{2}{*}{ Model } & \multicolumn{2}{|c|}{ Unstandardized Coefficients } & \multirow{2}{*}{$\begin{array}{c}\text { Standardized Coefficients } \\
\text { Beta }\end{array}$} & \multirow{2}{*}{$t$} & \multirow{2}{*}{ Sig. } \\
\hline & & B & Std. Error & & & \\
\hline \multirow[t]{2}{*}{1} & (Constant) & -3.903 & 4.565 & & -.855 & .397 \\
\hline & Budaya kerja & .283 & .076 & .301 & 3.726 & .001 \\
\hline
\end{tabular}

a Dependent variable: Komitmen kerja

Pada table 3 diperoleh nilai $t_{\text {hitung }}$ sebesar 3.726. Penelitian ini menggunakan taraf signifikansi $(\alpha ; 0,05)$ dan derajat kebebasan $(\mathrm{DK})$ dengan ketentuan $\mathrm{DK}=\mathrm{n}-2$, atau $52-2=50$. Dengan ketentuan tersebut, diperoleh nilai $t_{\text {tabel }}$ sebesar 1.852. Dengan kriteria hipotesis sebagai Jika $t_{\text {hitung }}>$ $t_{\text {tabel, }}$, maka $\mathrm{H}_{0}$ ditolak dan $\mathrm{H}_{\mathrm{a}}$ diterima dan jika $\mathrm{t}_{\text {hitung }}<\mathrm{t}_{\text {tabel, }}$, maka $\mathrm{H}_{0}$ diterima dan $\mathrm{H}_{\mathrm{a}}$ ditolak. 


\section{Pengaruh Kepuasan Kerja terhadap Komitmen kerja Guru}

Untuk mengetahui pengaruh kepuasan kerja terhadap komitmen kerja guru di SMA Negeri I Dolok Batu Nanggar digunakan uji-t, sedangkan untuk melihat besarnya pengaruh digunakan angka beta atau standardized coefficient.

Tabel 4. Coeficients ${ }^{\mathrm{a}}$ Pengaruh Kepuasan Kerja terhadap Komitmen Kerja

\begin{tabular}{|c|c|c|c|c|c|c|}
\hline & \multirow{2}{*}{ Model } & \multicolumn{2}{|c|}{ Unstandardized Coefficients } & \multirow{2}{*}{$\begin{array}{c}\text { Standardized } \\
\text { Coefficients } \\
\text { Beta } \\
\end{array}$} & \multirow{2}{*}{$t$} & \multirow{2}{*}{ Sig. } \\
\hline & & B & Std. Error & & & \\
\hline \multirow[t]{2}{*}{1} & (Constant) & -3.903 & 4.565 & & -.855 & .397 \\
\hline & Kepuasan kerja & .610 & .084 & .605 & 7.245 & .000 \\
\hline
\end{tabular}

Berdasarkan table 4 diperoleh nilai $t_{\text {hitung }}$ sebesar 7.245. Penelitian ini menggunakan taraf signifikansi $(\alpha ; 0,05)$ dan derajat kebebasan (DK) dengan ketentuan $\mathrm{DK}=\mathrm{n}-2$, atau $52-2=50$. Dengan ketentuan tersebut, diperoleh nilai $t_{\text {tabel }}$ sebesar 1.852. Dengan kriteria hipotesis jika $t_{\text {hitung }}>$ $t_{\text {tabel, }}$, maka $\mathrm{H}_{0}$ ditolak dan $\mathrm{H}_{\mathrm{a}}$ diterima dan jika $\mathrm{t}_{\text {hitung }}<\mathrm{t}_{\text {tabel }}$, maka $\mathrm{H}_{0}$ diterima dan $\mathrm{H}_{\mathrm{a}}$ ditolak.

Pengaruh Iklim Organisasi Sekolah, Budaya Kerja Guru dan Kepuasan Kerja terhadap Komitmen Kerja Guru

Untuk melihat pengaruh iklim organisasi sekolah, budaya kerja guru dan kepuasan kerja terhadap komitmen kerja guru di SMA Negeri I Dolok Batu Nanggar secara simultan, maka dapat dilihat dari hasil perhitungan dalam model summary, khususnya angka $R_{\text {square }}$ pada Tabel 5

Tabel 5. Model Summary ${ }^{\mathrm{b}}$ Pengaruh Iklim Organisasi Sekolah, Budaya Kerja Guru dan Kepuasan Kerja Terhadap Komitmen Kerja Guru

\begin{tabular}{ccccc}
\hline Model & $\mathrm{R}$ & $R_{\text {Square }}$ & Adjusted $R_{\text {Square }}$ & Std. Error of the Estimate \\
\hline 1 & $.849^{\mathrm{a}}$ & .721 & .704 & 1.87407
\end{tabular}

a Predictors: (Constant), Iklim organisasi, budaya kerja, kepuasan kerja

b Dependent variable: Komitmen kerja

Tabel 5 menjelaskan bahwa besarnya angka $R_{\text {Square }}\left(\mathrm{R}^{2}\right)$ adalah 0.721 . Angka tersebut mempunyai maksud pengaruh iklim organisasi sekolah, budaya kerja guru dan kepuasan kerja terhadap komitmen kerja guru di SMA Negeri I Dolok Batu Nanggar sebesar $72.10 \%$, sedangkan sisanya sebesar $27.90 \%(100 \%-72.10 \%)$ dipengaruhi oleh faktor-faktor lain yang tidak diteliti. Dengan kata lain variabilitas komitmen kerja guru dapat diterangkan oleh variabel iklim organisasi sekolah, budaya kerja guru dan kepuasan kerja adalah $72.10 \%$, sedangkan sisanya sebesar $27.90 \%$ disebabkan oleh variabel-variabel lain yang tidak diteliti atau tidak dimasukkan dalam model penelitian ini.

Tabel 6. Anova ${ }^{\mathrm{b}}$ Pengaruh Iklim Organisasi Sekolah, Budaya Kerja Guru, dan Kepuasan Kerja Terhadap Komitmen Kerja Guru

\begin{tabular}{clccccc}
\hline Model & & Sum of Squares & $d f$ & Mean Square & $F$ & \multirow{2}{*}{ Sig. } \\
\cline { 1 - 5 } 1 & Regression & 435.725 & 3 & 145.242 & 41.354 & $.000^{\mathrm{a}}$ \\
& Residual & 168.582 & 48 & 3.512 & & \\
& Total & 604.308 & 51 & & & \\
\hline
\end{tabular}

a Predictors: (Constant), Iklim organisasi, budaya kerja, kepuasan kerja

b Dependent variable: Komitmen kerja

Pada tabel 6 diperoleh nilai $F_{\text {hitung }}$ sebesar 41.354. Penelitian ini menggunakan taraf signifikansi ( $\alpha$ : 0.05) dan derajat kebebasan (DK) dengan ketentuan numerator : jumlah variabel -1 atau $4-1=3$, dan jumlah sampel dikurang 4 atau $52-3=49$. Dengan ketentuan tersebut, diperoleh 
nilai $F_{\text {tabel }}$ sebesar 2.952. Dengan kriteria hipotesis jika $F_{\text {hitung }}>F_{\text {tabel, }}$, maka $H_{0}$ ditolak dan $H_{a}$ diterima dan jika $\mathrm{F}_{\text {hitung }}<\mathrm{F}_{\text {tabel, }}$, maka $\mathrm{H}_{0}$ diterima dan $\mathrm{H}_{\mathrm{a}}$ ditolak.

\section{Analisis Regresi Linier Berganda}

Analisis regresi linier berganda antara variabel iklim organisasi sekolah, budaya kerja guru dan kepuasan kerja terhadap komitmen kerja guru di SMANegeri I Dolok Batu Nanggar, maka dapat dilihat dari persamaan regresinya, dan dari output SPSS diperoleh data pada Tabel 7.

Tabel 7. Hasil Uji Statistik Koefisien Regresi Pengaruh Iklim Organisasi Sekolah, Budaya Kerja Guru, dan Kepuasan Kerja Terhadap Komitmen Kerja Guru

\begin{tabular}{|c|c|c|c|c|c|c|}
\hline & \multirow{2}{*}{ Model } & \multicolumn{2}{|c|}{ Unstandardized Coefficients } & \multirow{2}{*}{$\begin{array}{l}\text { Standardized Coefficients } \\
\text { Beta }\end{array}$} & \multirow{2}{*}{$t$} & \multirow{2}{*}{ Sig } \\
\hline & & $\mathrm{B}$ & Std. Error & & & \\
\hline \multirow{4}{*}{1} & (Constant) & -3.903 & 4.565 & & -.855 & .397 \\
\hline & Iklim organisasi & .220 & .087 & .205 & 2.516 & .015 \\
\hline & Budaya kerja & .283 & .076 & .301 & 3.726 & .001 \\
\hline & Kepuasan kerja & .610 & .084 & .605 & 7.245 & .000 \\
\hline
\end{tabular}

a Predictors: (Constant), Iklim organisasi, budaya kerja, kepuasan kerja

b Dependent variable: Komitmen kerja

Berdasarkan Tabel 7 dapat dibuat persamaan regresi $\mathrm{Y}=-3.903+0.220 \mathrm{X}_{1}+0.283 \mathrm{X}_{2}+$ $0.610 \mathrm{X}_{3}$. Nilai komitmen kerja guru di SMA Negeri I Dolok Batu Nanggar sebesar -3.903 , yang mana nilai dari variabel iklim organisasi sekolah, budaya kerja guru dan kepuasan kerja diabaikan.

Pembahasan

Berdasarkan perhitungan untuk melihat pengaruh iklim organisasi sekolah terhadap komitmen kerja guru diperoleh nilai $t_{\text {hitung }}>t_{\text {tabel }}(2.516>1.852)$ dan nilai signifikasi $0,015<0,05$, sehingga $\mathrm{H}_{0}$ ditolak dan $\mathrm{H}_{\mathrm{a}}$ diterima. Artinya variabel iklim organisasi sekolah berpengaruh positif dan signifikan terhadap komitmen kerja guru di SMA Negeri I Dolok Batu Nanggar. Besarnya pengaruh iklim organisasi sekolah terhadap komitmen kerja guru sebesar 0.205 atau $20.50 \%$. Untuk perhitungan pengaruh budaya kerja guru terhadap komitmen kerja guru diperoleh nilai $t_{\text {hitung }}>t_{\text {tabel }}$ $(3.726>1.852)$ dan nilai signifikasi $0,001<0,05$, sehingga $\mathrm{H}_{0}$ ditolak dan $\mathrm{H}_{\mathrm{a}}$ diterima. Artinya variabel budaya kerja guru berpengaruh positif dan signifikan terhadap komitmen kerja guru di SMA Negeri I Dolok Batu Nanggar. Besarnya pengaruh budaya kerja guru terhadap komitmen kerja guru sebesar 0.301 atau $30.10 \%$.

Sedangkan perhitungan untuk melihat pengaruh kepuasan kerja terhadap komitmen kerja guru diperoleh nilai $\mathrm{t}_{\text {hitung }}>\mathrm{t}_{\text {tabel }}(7.245>1.852)$ dan nilai signifikasi $0,000<0,05$, sehingga $\mathrm{H}_{0}$ ditolak dan $\mathrm{H}_{\mathrm{a}}$ diterima. Artinya variabel kepuasan kerja berpengaruh positif dan signifikan terhadap komitmen kerja guru di SMA Negeri I Dolok Batu Nanggar. Besarnya pengaruh kepuasan kerja terhadap komitmen kerja guru sebesar 0.605 atau $60.50 \%$. Adapun perhitungan pengaruh iklim organisasi sekolah, budaya kerja guru dan kepuasan kerja terhadap komitmen kerja guru diperoleh nilai $F_{\text {hitung }}>F_{\text {tabel }}(41.354>2.952)$ dan nilai signifikasi $0.000<0.05$, sehingga $\mathrm{H}_{0}$ ditolak dan $\mathrm{H}_{\mathrm{a}}$ diterima. Ini mengartikan bahwa variabel iklim organisasi sekolah, budaya kerja guru dan kepuasan kerja berpengaruh positif dan signifikan terhadap komitmen kerja guru di SMA Negeri I Dolok Batu Nanggar. Dengan demikian model regresi ini sudah layak dan benar dan dapat disimpulkan bahwa variabel iklim organisasi sekolah, budaya kerja guru dan kepuasan kerja secara simultan berpengaruh terhadap komitmen kerja guru di SMA Negeri I Dolok Batu Nanggar.

Persamaan di atas menjelaskan bahwa koefisien regresi $\mathrm{X}_{1}$ (iklim organisasi sekolah) mempunyai nilai positif yaitu 0.220 , hal ini menunjukkan bahwa variabel iklim organisasi sekolah mempunyai pengaruh positif terhadap komitmen kerja guru di SMA Negeri I Dolok Batu Nanggar. Hal bila iklim organisasi sekolah meningkat 1\%, maka komitmen kerja guru akan bertambah 2.20. Koefisien regresi $\mathrm{X}_{2}$ (budaya kerja guru) juga mempunyai nilai positif yaitu 0.283 , hal ini menunjukkan bahwa variabel budaya kerja guru mempunyai pengaruh positif terhadap komitmen 
kerja guru di SMA Negeri I Dolok Batu Nanggar. Hal bila budaya kerja guru meningkat 1\%, maka komitmen kerja guru akan bertambah 2.83. Koefisien regresi $\mathrm{X}_{3}$ (kepuasan kerja) juga mempunyai nilai positif yaitu 0.610 , hal ini menunjukkan bahwa variabel kepuasan kerja mempunyai pengaruh positif terhadap komitmen kerja guru di SMA Negeri I Dolok Batu Nanggar. Hal bila kepuasan kerja kepala sekolah meningkat 1\%, maka komitmen kerja guru akan bertambah 6.10.

\section{SIMPULAN}

Berdasarkan pada analisis dan evaluasi data di atas, maka simpulan dari penelitian ini yaitu variabel iklim organisasi sekolah berpengaruh positif dan signifikan terhadap komitmen kerja guru di SMA Negeri I Dolok Batu Nanggar sebesar 0.205 atau 20.50\%, dengan nilai $t_{\text {hitung }}>t_{\text {tabel }}(2.516>$ 1.852), variabel budaya kerja guru berpengaruh positif dan signifikan terhadap komitmen kerja guru di SMA Negeri I Dolok Batu Nanggar sebesar 0.301 atau 30.10\%, dengan nilai $t_{\text {hitung }}>t_{\text {tabel }}(3.726>$ 1.852), variabel kepuasan kerja berpengaruh positif dan signifikan terhadap komitmen kerja guru di SMA Negeri I Dolok Batu Nanggar sebesar 0.605 atau 60.50\%, dengan nilai $t_{\text {hitung }}>t_{\text {tabel }}(7.245>$ 1.852), variabel iklim organisasi sekolah, budaya kerja guru dan kepuasan kerja berpengaruh positif dan signifikan terhadap komitmen kerja guru di SMA Negeri I Dolok Batu Nanggar sebesar $72.10 \%$, sedangkan sisanya sebesar $27.90 \%$ dipengaruhi oleh faktor-faktor lain yang tidak diteliti, dan persamaan regresi dalam penelitian ini adalah $\mathrm{Y}=-3.903+0.220 \mathrm{X}_{1}+0.283 \mathrm{X}_{2}+0.610 \mathrm{X}_{3}$.

\section{DAFTAR PUSTAKA}

Ilahi, D. K., Mukzam, M. D., \& Prasetya, A. (2017). Pengaruh kepuasan kerja terhadap disiplin kerja dan komitmen organisasional (Studi pada karyawan PT. PLN (Persero) distribusi Jawa Timur area Malang). Jurnal Administrasi Bisnis (JAB), 44(1), 31-39.

Iqbal, S., Ehsan, S., Rizwan, M., \& Noreen, M. (2014). The impact of organizational commitment, job satisfaction, job stress and leadership support on turnover intention in educational institutes. International Journal of Human Resource Studies, 4(2), 181-195. doi:http://dx.doi.org/10.5296/ijhrs.v4i2.5906

Mahanani, I. W., Lubis, N., \& Widiartanto, W. (2014). Pengaruh budaya kerja dan kepuasan kerja terhadap kinerja karyawan dengan komitmen karyawan sebagai variabel antara (Studi kasus pada karyawan bagian produksi cetak surat kabar PT. Masscom Graphy Semarang). Jurnal Ilmu Administrasi Bisnis, 3(4), 355-365. Retrieved from https:/ejournal3.undip.ac.id/index.php/jiab/article/view/6592/6362

Manzoor, S. R., Ullah, H., Hussain, M., \& Ahmad, Z. M. (2011). Effect of teamwork on employee performance. International Journal of Learning and Development, 1(1), 110-126. doi:http://dx.doi.org/10.5296/ijld.v1i1.1110

Muayyad, D. M., \& Gawi, A. I. O. (2016). Pengaruh Kepuasan Kerja terhadap Produktivitas Kerja Pegawai Bank Syariah X Kantor Wilayah II. Jurnal Manajemen dan Pemasaran Jasa, 9(1), 75-98. doi:https://doi.org/10.25105/jmpj.v9i1.1396

Nurhasnawati, \& Subhan, M. (2018). Pengaruh antara iklim organisasi dan kepuasan kerja dengan organizatioanal citizenship behaviour pada guru MIN se kota Pekanbaru. Indonesian Journal of Islamic Educational Management (IJIEM), 1(2), 96-111. doi:http://dx.doi.org/10.24014/ijiem.v1i2.6649

Puspitasari, D., \& Asyanti, S. (2011). Faktor yang paling berpengaruh terhadap komitmen kerja perawat panti Wreda di Surakarta. Jurnal Psikologi UNDIP, 9(1), 57-64. doi:https://doi.org/10.14710/jpu.9.1

Putri, F. I. (2014). Hubungan motivasi kerja dengan komitmen kerja karyawan di Balai Pendidikan dan Pelatihan Sosial. Jurnal Bahana Manajemen Pendidikan, 2(1), 220-831. doi:https://doi.org/10.24036/bmp.v2i1.3756 
Rizqina, Z. A., Adam, M., \& Chan, S. (2017). Pengaruh budaya kerja, kemampuan, dan komitmen kerja terhadap kepuasan kerja pegawai serta dampaknya terhadap kinerja Badan Pengusahaan Kawasan Perdagangan Bebas dan Pelabuhan Bebas Sabang (BPKS). Jurnal Magister Manajemen, 1(1), 59-69.

Robbins, S. P., \& dan Judge, T. A. (2012). Organizational behavior. Upper Saddle River, New Jersey: Pearson Education, Inc.

Setiawan, K. C. (2015). Pengaruh iklim organisasi terhadap kinerja karyawan level pelaksana di divisi operasi PT. Pusri Palembang. Psikis: Jurnal Psikologi Islami, 1(1), 23-32. Retrieved from http://jurnal.radenfatah.ac.id/index.php/psikis/article/view/554

Steers, R. M., \& Porter, L. W. (2008). Motivation and work behavior. New York: Mc Graw-Hill Book Company.

Widyastuti, N., \& Palupiningdyah, P. (2015). Pengaruh kepuasan dan motivasi kerja terhadap kinerja karyawan dengan Organizational Citizenship Behavior (OCB) sebagai variabel intervening. Management Analysis Journal, 4(1). doi:https://doi.org/10.15294/maj.v4i1.7221 